\title{
An Optimal Investment Returns with N-Step Utility Functions
}

\author{
EGHWERIDO Joseph Thomas ${ }^{1, a^{*}}$ and OBILADE Titilola ${ }^{2, b}$ \\ ${ }^{1}$ Department of Mathematics and Computer Science, \\ Federal University of Petroleum Resources Effurun, \\ P.M.B 1221, Effurun, Delta State, Nigeria. \\ 2 Department of Mathematics, \\ Obafemi Awolowo University, Ile-Ife, Nigeria \\ aeghwerido.joseph@fupre.edu.ng, ${ }^{b}$ tobilade@yahoo.com,
}

\begin{abstract}
Keywords: Neutral probability, Investment performances, Market setting, Capital Market, Utility
\end{abstract} functions.

\begin{abstract}
In this paper, we shall validate the optimal payoff of an investment with an N-step utility function, $[6,7]$, such that $\mathrm{H}^{*}$ is the payoff at time $\mathrm{N}$ in every possible state say $2 \mathrm{n}$; in an $\mathrm{N}$ period market setting. Negative exponential, logarithm, square root and power utility functions were considered as the market structures change according to a Markov chain. These models were used to predict the performances of some selected companies in the Nigeria Capital Market. The estimates for models design parameters p, q, p', q' correspond to halving or doubling of investment. The performance of any utility function is determined by the ratio q: q' of the probability of rising to falling as well as the ratio $\mathrm{p}$ : p' of the risk neutral probability measure of rising to the falling.
\end{abstract}

\section{Introduction}

Portfolio management is all inclusive activity in our daily life. For an example, one has got a particular amount of money and tries to use it in such a way that one can draw the maximum possible utility from the corresponding activities. This principle covers numerous situations of our daily life. The problem of portfolio optimization of an investor trading in different assets is to choose an optimal investment that can maximized his/her initial stake. This may involve shares of which asset he/she should hold at any trading time, in order to maximize some subjective (depending on his preferences) criterion which rely on his total wealth and/or consumption, Eghwerido et al. (2015). The foremost approach to solving problem of this type is called meanvariance approach pioneered by Markowitz H. (1952) in a one-period decision model. Though, it still has great importance in real life applications, and is widely applied in the risk management departments of banks for example. The reasons for this, is being the simplicity with which the algorithm can be implemented, and that it requires no special knowledge on probability (only expectation and covariance of random variables are enough). However, the main drawback of this approach is the static nature of the problem: after the decision concerning the allocation of initial wealth to the different shares has been made at the beginning of the period, no further actions are allowed until the end of the initial portfolio is chosen, the investor's job is complete and his/her only feasible action is to watch the prices move without the possibility to intervene. This is an extreme oversimplification of reality and totally ignores the highly volatile behaviour and dynamic nature of prices. In contrast, continuous-time models offer more satisfying solutions to these problems.

In financial market where investors are faced with uncertainty, the strategy that optimizes the return of an investment in assets is in general not known. Suppose that the investor compares random returns whom he knows the probability distributions on some probability space $(\Omega, F, P)$, hence, a portfolio manager maximizes the expected utility of his terminal wealth in a complete market with a stochastic interest rate [1], which follows the affine dynamics [2] that allows partial risk transfer between the contributor and the fund manager [3]. L. Delong et al. [4] stated that such asset allocation strategies will be achieved only in pre-retirement accumulation phase. Thus, the 
optimal investment strategy follow a composite asymptotic expansion [5]. Furthermore, Eghwerido et al. $[6,7]$ established a case where we have negative exponential, logarithmic, square root, power utility functions with a returns on investment and their generalized form; while [8] proposed asset allocation for payment of long-term liability in a multi-period discrete time where [9] determined an equilibrium strategies for maximizing exponential utility. Korn [10] emphasized optimal investment. Also, [11] deals with investor which has the opportunity to put her wealth into derivatives with counter party risk or credit derivatives. Korn [12] considered a portfolio process yielding the highest worst-case bound where trading in the risky asset is stopped if a state process hits a predefined barrier [13] hence, mathematical theory of speculative prices through a feedback was developed elaborately[14, 15].

The mean-variance criterion of Markowitz [16] in a one-period decision model that risk is only measured in terms of the variance of the portfolio return was criticized; that symmetric form of the variance has the undesirable side effect of not only bounding possible losses, but also possible gain [17]. Mulvey et al. [18] stated that multi-stage simulation and optimization are effective for solving long-term financial planning problems. Oshorne develops the proposition that it is not absolute price changes but the logarithmic price changes which are independent of each other[19]; [20] emphasize on characterization of optimal control for diffusion processes; while Roger considered a case where an investor faced with the classical Merton problem of optimal investment in a logBrownian asset and a fixed-interest bond, but constrained only to change portfolio [21], [22] stress on utility maximization in incomplete markets through semi-martingale model for incomplete markets, and to characterize it via the associated dual problem. Schweizer [23] developed area of pricing and hedging contingent claims in an incomplete market by means of a quadratic criterion and [24] showed that they may be represented by an expected utility criterion. More precisely, by denoting $\rightleftharpoons$ the preference order on the set of random returns, we say that $\ddot{\sim}$ satisfies the criterion if and only if there exists some increasing function $U$ from $\Re$ into $\Re$ called utility function, such that

$$
\mathrm{X}_{1} \quad \mathrm{X}_{2} \Leftrightarrow \mathrm{E}\left[\mathrm{U}\left(\mathrm{X}_{1}\right)\right]>\mathrm{E}\left[\mathrm{U}\left(\mathrm{X}_{2}\right)\right] .
$$

The increasing property of the utility functions means that the investor prefers more wealth. Thus, the choice of the utility function allows investor the notions of risk aversion and risk premium related uncertainty, Hence the strategy that delivers the optimal terminal wealth.

\section{Preliminary}

Due to the high liquidity, leverage effects and their non-linear pay-off profile, together with options and other derivatives are now widely used as an investment opportunity. However, a straight forward generalization of the stochastic control approach leads to a much more complicated form of the Hamilton Jacobi Bellman equations (HJB-equations). Thus, the martingale approach of portfolio optimization deals with this problem.

The pay-off for $\mathrm{N}$ period model, $\mathrm{Y}_{\mathrm{i}}$ at time step $\mathrm{i}$ is given by

$$
\mathrm{Y}_{\mathrm{i}}=2^{2(\mathrm{n}-\mathrm{i})}
$$

with probability ${ }^{2 n} C_{i}(1-p){ }^{2 n-i} p^{i} ; i=0,1,2, \ldots, 2 n$ for an even step or $Y_{i}=2^{2(n-i)-1}$ with probability ${ }^{2 n-1} C_{i}(1-p)^{2 n-i-1} p^{i} ; i=0,1,2, \ldots, 2 n-1$ for an odd step and for initial capital $x$ with probability of increase and decrease $q$ and $p$ respectively and risk-neutral probability measure q'.

The dynamic optimization problem stated can be represented as a static optimization problem over terminal wealth:

Subject to

$$
\mathrm{V}_{0}(\mathrm{x})=\sup _{\mathrm{H}} \mathrm{E}[\mathrm{U}(\mathrm{H})]
$$

$$
\mathrm{E}[\mathrm{H}]^{\mathrm{Q}}=\mathrm{x}
$$

where $\mathrm{H}$ denotes state, $\mathrm{U}$ the utility function and $\mathrm{Q}$ risk neutral probability. The concept of martingale is motivated by the concept of sums of independent random variables. Any situation where the past behaviour of the process being modeled can reasonably be taken to influence its future behaviour gives rise to martingales. 
Theorem 1.0. A sequence of random variables and Borel fields. $\left\{X_{n}, F_{n}\right\}$ is called a martingale Kai Lai Chung, (1968) if and only if we have for each $n$

- $\mathrm{F}_{\mathrm{n}} C \mathrm{~F}_{\mathrm{n}+1}$ and $\mathrm{X}_{\mathrm{n}} \in \mathrm{F}_{\mathrm{n}}$ i.e. $\left\{\mathrm{X}_{\mathrm{n}}\right\}$ is adapted to $\left\{\mathrm{F}_{\mathrm{n}}\right\}$

- $\mathrm{E}\left\{\left|\mathrm{X}_{\mathrm{n}}\right|\right\}<\infty$

- $\mathrm{X}_{\mathrm{n}}=\mathrm{E}\left\{\mathrm{X}_{\mathrm{n}+1} \mid \mathrm{F}_{\mathrm{n}}\right\}$.

Remark 1.0. When a process $(X n: n \geq 0)$ satisfies condition (i), says that $(X n: n \geq 0)$ is adapted to $(F n: n \geq 0)$. Suppose $P_{t}$ is a time series process and $I_{t-1}=\left\{P_{t-1}, P_{t-2} \ldots\right\}$ is the information set available at time $t-1$. Then $\left\{\mathrm{P}_{\mathrm{t}}\right\}$ is called a martingale process with drift $\alpha$ if

$$
\mathrm{P}_{\mathrm{t}}=\alpha+\mathrm{P}_{\mathrm{t}-1}+\mathrm{X}_{\mathrm{t}}
$$

where $X_{t}$ is a stationary time series process such that

$$
\mathrm{E}\left(\mathrm{X}_{\mathrm{t}} \mid \mathrm{I}_{\mathrm{t}-1}\right)=0 \text {. }
$$

The initial stock price can go either up to $S^{\mathrm{u}}$ or down to $S^{\mathrm{d}}$. If the interest rate is $\mathrm{R}>(0)$, we note that $\mathrm{S}^{\mathrm{d}} \leq(1+\mathrm{R}) \leq \mathrm{S}^{\mathrm{u}}, \mathrm{i}=0,1,2, \ldots 2 \mathrm{n}$; and $\mathrm{p}+\mathrm{q}=1$; where $\mathrm{q}^{\prime}$ is the risk-neutral probability given as

$$
q^{\prime}=\frac{(1+R) S-S^{a}}{S^{u}-S^{d}}
$$

The unique risk neutral probability measure transforms the stock price into martingale by assigning the small probability to upward movement and p' to downward movement and for a system with $\mathrm{p}=$ p' all the states will have same results irrespective of doubling and halving.

The following results from Eghwerido et al. [6] will be quite useful for our considerations below.

For a choice of negative exponential return on investment is given by

$$
\frac{e^{-\gamma h}}{e^{-\gamma x}}=\left[\frac{p\left(1-p^{\prime}\right)}{p \cdot(1-p)}\right] 2 n p^{\prime}-i
$$

Suppose we want an optimal logarithmic rate of return, then

$$
\mathrm{h} * \mathrm{i}=x\left(\frac{p}{p^{i}}\right)^{i}\left(\frac{1-p}{1-p^{\prime}}\right)^{2 n-i}
$$

Thus, the ratio of $\mathrm{h}_{\mathrm{i}}{ }_{\mathrm{i}}$ to $\mathrm{x}$ for an even $\mathrm{N}$-step will be

$$
\left(\frac{h * i}{x}\right)^{3 / 2}=\left(\frac{p}{p^{\prime}}\right)^{i}\left(\frac{1-p}{1-p^{\prime}}\right)^{2 n-i}
$$

And for odd N-step

$$
\left(\frac{h_{i}^{*}}{x}\right)=\left[\frac{p}{p^{\prime}}\right]^{i}\left[\frac{1-p}{1-p^{\prime}}\right]^{2 n-i-1}
$$

A market structure with a square root utility function with even step structure is given as

$$
\frac{U(h)}{U(x)}=\left[\frac{h_{i}^{*}}{x}\right]^{1 / 2}=\left[\frac{p}{p^{\prime}}\right]^{i}\left[\frac{1-p}{1-p^{\prime}}\right]^{i}\left[\frac{(1-p)^{2}}{1-p^{\prime}}\right]^{n}\left[\frac{p^{\prime}}{p^{\prime}(1-p)^{2}+p^{2}\left(1-p^{\prime}\right)}\right]^{n}
$$

The power utility function is a generalization of square root utility function. Thus, for an investor with power utility function return we have,

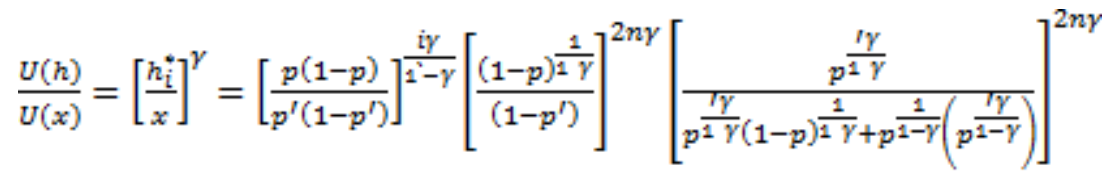

\section{Optimal Strategy}

The strategy generating the optimal wealth resulted in the optimal wealth $\mathrm{H}^{*}=\left(\mathrm{h}_{1}{ }_{1}, \mathrm{~h}_{2}{ }_{2} \ldots \mathrm{h}^{*}{ }_{2 \mathrm{n}}\right)$ at time $\mathrm{N}$ in every $2 \mathrm{n}$ possible states. We now compute the strategy that will deliver this terminal 
wealth, i.e. such that $\mathrm{X}_{2 \mathrm{n}}^{\mathrm{x} \alpha},=\mathrm{H}^{*}$. We denote the strategy by $\alpha_{2 \mathrm{n}-1}^{\mathrm{u}}$ when it goes up and $\alpha_{2 \mathrm{n}-1}^{\mathrm{d}}$ when it goes down; the value of the strategy $\alpha_{2 n-1}$ decided at time $t=2 n-1$.

Thus, the wealth value at time $t$ is given by

$$
\begin{gathered}
X_{0}^{x, \alpha}=\left(\alpha_{0} \frac{S_{1}}{S_{0}}+\left(1-\alpha_{0}\right)\right) X=h_{0}^{*} \\
X_{1}^{x, \alpha}=\left(\alpha_{1}^{u} \frac{S_{2}}{S_{1}}+\left(1-\alpha_{1}^{u}\right)\right) X_{0}^{x, \alpha}=h_{1}^{*} \\
X_{2}^{x, \alpha}=\left(\alpha_{2}^{u} \frac{S_{3}}{S_{2}}+\left(1-\alpha_{2}^{u}\right)\right) X_{1}^{x, \alpha}=h_{2}^{*}
\end{gathered}
$$

On and on to

$$
\begin{gathered}
X_{2 n-1}^{x, \alpha}=\left(\alpha_{2 n-2}^{u} \frac{S_{2 n-1}}{S_{2 n-2}}+\left(1-\alpha_{2 n-2}^{u}\right)\right) X_{2 n-3}^{x, \alpha}=h_{2 n-2}^{*} \\
X_{2 n-1}^{x, \alpha}=\left(\alpha_{2 n-1}^{u} \frac{S_{2 n}}{S_{2 n-1}}+\left(1-\alpha_{2 n-1}^{u}\right)\right) X_{2 n-2}^{x, \alpha}=h_{2 n-1}^{*} \\
X_{2 n}^{x, \alpha}=\left(\alpha_{2 n}^{u} \frac{S_{2 n+1}}{S_{2 n}}+\left(1-\alpha_{2 n}^{u}\right)\right) X_{2 n-1}^{x, \alpha}=h_{2 n}^{*}
\end{gathered}
$$

This is some sort of multiplicative effect of the wealth $h_{j}$ at time $\mathrm{j}$, a function of the strategy $\alpha=\left(\alpha_{t}\right) t=0,1, \ldots, 2 \mathrm{n}$ representing the fraction of wealth invested in stock at time $\mathrm{t}$ with the value of $\alpha_{t}$ chosen after observing the stock price $S_{t}$ at time t.

$$
h_{j}^{*}=X_{j}^{x, \alpha}=\prod_{i=1}^{j-1}\left(\alpha_{i-1}^{u} \frac{s_{i}}{s_{i-1}}+\left(1-\alpha_{i-1}^{u}\right)\right) x
$$

Thus, the strategy generating the optimal wealth is given as,

$$
\alpha_{0}=\frac{S_{0}\left(h_{0}^{*}-x\right)}{x\left(S_{1}-S_{0}\right)}
$$

and

$$
\alpha_{0}=\frac{s_{i}\left(h_{i+1}^{*}-h_{i}^{*}\right)}{h_{i-1}^{*}\left(s_{i+1}-s_{i}\right)}=\alpha_{i}^{d}
$$

for $\mathrm{i}=1,2,3, \ldots, 2 \mathrm{n}$

\section{Material and Methods}

Data were collected randomly based on their performance from different key sectors for 236 days from some companies quoted in the Nigeria Capital Market; which include Custodian and allied insurance plc (CA), Dangote cement plc (DC), Fidson health-care plc (FD), First bank plc (FB), Honey-well Flour Mill plc (HF) and Mrs Oil Nig. plc (MRS). Since the market is currently on a confidence re-building process and it is considered that the nature of the analysis is such that the current situation may be more relevant than an historical situation.

The data were smoothened to eliminate periodic fluctuations and obtain some semblance of stationary series. The measure of comparison of the smoothened data are shown in Table (1) for measures MAPE, MAD and MSD imply Mean Absolute Percentage Error, Mean Absolute Deviation and Mean Square Deviation respectively. 
Table 1. Details oferror ofmoving average smoothened by 4 point and 2 point for weekly maximum $\left(\mathrm{M}_{4}, \mathrm{M}_{2}\right)$ and minimum $\left(\mathrm{m}_{4}, \mathrm{~m}_{2}\right)$ stock price by various companies.

\begin{tabular}{|c|c|c|c|c|c|}
\hline company & Errors & $\mathrm{m}_{4}$ & $\mathrm{~m}_{2}$ & $\mathrm{M}_{4}$ & $\mathrm{M}_{2}$ \\
\hline \multirow{4}{*}{ CA } & MAPE & 10.2917 & 7.8523 & 9.9491 & $* 7.4145$ \\
\cline { 2 - 6 } & MAD & 0.1892 & 0.1479 & 0.1955 & $* 0.1475$ \\
\cline { 2 - 6 } & MSD & 0.0597 & 0.0403 & 0.0624 & $* 0.0401$ \\
\hline \multirow{4}{*}{ DC } & MAPE & 4.1521 & 3.4344 & 3.8209 & $* 3.2840$ \\
\cline { 2 - 6 } & MAD & 4.5060 & 3.7024 & 4.2554 & $* 3.6385$ \\
\cline { 2 - 6 } & MSD & 28.8850 & 21.8085 & 26.8494 & $* 21.6812$ \\
\hline \multirow{4}{*}{ FD } & MAPE & 12.7679 & 10.3337 & 11.4034 & $* 9.2289$ \\
\cline { 2 - 6 } & MAD & 0.1196 & 0.0980 & 0.1157 & $* 0.0958$ \\
\cline { 2 - 6 } & MSD & 0.0238 & 0.0164 & 0.0226 & $* 0.0151$ \\
\hline \multirow{5}{*}{ FB } & MAPE & 6.6263 & 5.0643 & 5.9156 & $* 4.8346$ \\
\cline { 2 - 6 } & MAD & 0.6433 & $* 0.4928$ & 0.6208 & 0.5065 \\
\cline { 2 - 6 } & MSD & 0.5805 & $* 0.3787$ & 0.6087 & 0.4022 \\
\hline \multirow{4}{*}{ HF } & MAPE & 10.3430 & 8.1514 & 10.3430 & $* 8.0596$ \\
\cline { 2 - 6 } & MAD & 0.2668 & $* 0.2177$ & 0.2841 & 0.2252 \\
\cline { 2 - 6 } & MSD & 0.1382 & 0.0932 & 0.1505 & $* 0.0902$ \\
\hline \multirow{4}{*}{ MRS } & MAPE & 5.3915 & 3.4773 & 5.1465 & $* 3.3812$ \\
\cline { 2 - 6 } & MAD & 2.2617 & 1.4785 & 2.1873 & $* 1.4542$ \\
\cline { 2 - 6 } & MSD & 13.8359 & 7.5396 & 12.9364 & $* 6.8142$ \\
\hline
\end{tabular}

*denotes a better smoothening.

We note that the smaller the performance measure, the better the smoothing. The following can be observed from Table (1). The probabilities $p$ and $q, p^{\prime}$ and q' were calculated for the values of $\mathrm{M}_{2}(\mathrm{i})$. This assigned 0 for values below the median and mean; 1 for values above the median and mean. This is to introduce a dichotomy in line with the model requirement of halving or doubling investment. We note that the smaller the performance measure, the better the smoothing. The following can be observed from Table (1).

1. For companies CA, DC, FD and MRS the best smoothing is provided by the 2 point weekly maximum moving average irrespective of the performance criteria.

2. For company FB the best smoothing is provided by the 2 point weekly maximum moving average based on the criterion MAPE (but 2 point weekly maximum moving average based on MAD and MSD).

3. For company HF the best smoothing is provided by the 2 point weekly maximum moving average based on the criteria MSD and MAPE (but 2 point weekly minimum moving average based on MAD).

4. Although 2 point weekly minimum moving average provided the best smoothing on MAD and MSD for FB and based on the criterion MAD for HF, the 2 point weekly maximum moving average gives very close competition.

5. Reading carefully, it is safe to adopt 2 point weekly maximum moving average for further analysis from this point onwards for all the companies.

Stationarity test of the different companies CA, DC, FD, FB, HF and MRS using differencing lag 2 and lag 4 were carried out. Test are shown in the Table (2) representing the Augmented DickeyFuller Test Equation, Adjusted R-squared, Akaike info criterion and Schwarz criterion at 1 percent using differencing lag $2 .{ }^{*}$ denoting the highest value in each of test criteria. 
Table 2. Test for Seasonality for VariousCompanies with Differencing Lag 4.

\begin{tabular}{|l|l|l|l|l|l|l|}
\hline & \multicolumn{1}{|c|}{ CA } & \multicolumn{1}{c|}{ DC } & \multicolumn{1}{c|}{ FB } & FD & HF & \multicolumn{1}{c|}{ MRS } \\
\hline ADF Test Statistic & $-8.46691 *$ & -4.726938 & -4.830368 & -5.784156 & -5.449728 & -4.492994 \\
\hline Adjusted R-Squared & $0.780724 *$ & 0.447643 & 0.424419 & 0.557537 & 0.567032 & 0.528015 \\
\hline Akaike info criterion & -2.764566 & $4.196380 *$ & 0.788731 & -3.077321 & -1.510226 & 2.475883 \\
\hline Schwarz criterion & -2.644122 & $4.316824 *$ & 0.909175 & -2.956877 & -1.389781 & 2.596327 \\
\hline 1 percent & -3.5814 & -3.5814 & -3.5814 & -3.5814 & -3.5814 & -3.5814 \\
\hline 5 percent & -2.9271 & -2.9271 & -2.9271 & -2.9271 & -2.9271 & -2.9271 \\
\hline 10 percent & -2.6013 & -2.6013 & -2.6013 & -2.6013 & -2.6013 & -2.6013 \\
\hline
\end{tabular}

\section{Results and Discussion}

Table (3) shows that probability $\mathrm{p}$ for rising is higher than that of falling for companies DC, FD, FB and MRS. While the reverse is the case for companies CA and HF.

Furthermore, the ratio $\mathrm{p} / \mathrm{p}$ ' for 2 point weekly maximum moving average is less than 1 for companies DC, FD, FB and MRS. While it is less than 1 for companies CA and HF. Also, the ratio $\mathrm{p} / \mathrm{p}$ ' for difference lag 2 is greater than 1 for companies CA, DC, FD, FB,HF and MRS. The case for difference of lag 4 is that $\mathrm{p} / \mathrm{p}$ 'is greater than 1 for companies FD, HF and MRS and lesser than 1 for companies CA, DC and FB.

Table 3. Estimation of parameters by company

\begin{tabular}{|l|llll|ll|ll|}
\hline \multirow{2}{*}{ Company } & \multicolumn{4}{|c|}{ M2 (i) } & \multicolumn{2}{c|}{ D2 } & \multicolumn{2}{c|}{ D4 } \\
\cline { 2 - 10 } & $\mathrm{p}$ & $\mathrm{q}$ & $\mathrm{p}$ & $\mathrm{q}$ & $\mathrm{p}$ & $\mathrm{q}$ & $\mathrm{p}$ & $\mathrm{q}$ \\
\hline Custodian & $24 / 49$ & $25 / 49$ & $25 / 49$ & $24 / 49$ & $16 / 47$ & $31 / 47$ & $1 / 3$ & $2 / 3$ \\
Dangote Cement & $27 / 49$ & $22 / 49$ & $25 / 49$ & $24 / 49$ & $21 / 47$ & $26 / 47$ & $26 / 45$ & $19 / 45$ \\
Fidson & $28 / 49$ & $21 / 49$ & $17 / 49$ & $32 / 49$ & $23 / 47$ & $24 / 47$ & $7 / 15$ & $8 / 15$ \\
First Bank & $25 / 49$ & $24 / 49$ & $24 / 49$ & $25 / 49$ & $21 / 47$ & $26 / 47$ & $5 / 9$ & $4 / 9$ \\
Honeywell & $23 / 49$ & $26 / 49$ & $26 / 49$ & $23 / 49$ & $13 / 47$ & $34 / 47$ & $4 / 15$ & $11 / 15$ \\
MRS & $25 / 49$ & $24 / 49$ & $24 / 49$ & $25 / 49$ & $17 / 47$ & $30 / 47$ & $4 / 15$ & $11 / 15$ \\
\hline
\end{tabular}

The ratio of hi* to $\mathrm{x}$ and the Return On Investment(ROI) produced by the models discussed were computed using the values of $\mathrm{p}, \mathrm{q}, \mathrm{p}^{\prime}$ and q' shown in Table 3.

Tables $(4,5$ and 6$)$ give the ratio $\left(\mathrm{hi}^{*} / \mathrm{x}\right)$ of pay-off value (hi*) of companies to the initial wealth $\mathrm{x}$ by companies by steps and days for the logarithm,square root and negative exponential models with difference lag 4 and the performance of different companies down the days and across the steps with * denoting highest ROI for each of the companies CA, DC, FB, FD, HF and MRS

Table 4. The Ratio (hi*/x) of Pay-off Value (hi*) of Companies to the Initial Wealth $\mathrm{x}$ by Companies by Steps and Days for the Logarithm Model with Difference Lag 4

\begin{tabular}{|c|c|c|c|c|c|c|c|c|c|}
\hline Days & Com & $\mathrm{i}=0$ & $\mathrm{i}=1$ & $i=2$ & $i=3$ & $i=4$ & $i=5$ & $i=6$ & $i=7$ \\
\hline \multirow{6}{*}{1} & $\mathrm{CA}$ & 0.5857 & 1.1245 & & & & & & \\
\hline & DC & 1.1308 & 1.0141 & & & & & & \\
\hline & FD & 0.6457 & 0.9840 & & & & & & \\
\hline & FB & $1.2145^{*}$ & 1.0121 & & & & & & \\
\hline & $\mathrm{HF}$ & 0.5235 & 1.2736 & & & & & & \\
\hline & MRS & 0.4461 & $1.2779 *$ & & & & & & \\
\hline \multirow{6}{*}{2} & $\mathrm{CA}$ & 0.3430 & 0.6586 & 1.2646 & 2.4280 & 4.6617 & & & \\
\hline & DC & 1.2786 & 1.1467 & 1.0285 & 0.9224 & 0.8272 & & & \\
\hline & FD & 0.4170 & 0.6354 & 0.9682 & 1.4753 & 2.2481 & & & \\
\hline & FB & $1.4750 *$ & $1.2292 *$ & 1.0243 & 0.8536 & 0.7113 & & & \\
\hline & $\mathrm{HF}$ & 0.2741 & 0.6668 & 1.6221 & 3.9461 & 9.5996 & & & \\
\hline & MRS & 0.1990 & 0.5701 & $1.6330 *$ & $4.6778 *$ & $13.400 *$ & & & \\
\hline \multirow{6}{*}{3} & $\mathrm{CA}$ & 0.2009 & 0.3858 & 0.7407 & 1.4220 & $22.730 *$ & 5.2422 & 10.065 & \\
\hline & $\mathrm{DC}$ & 1.4458 & 1.2967 & 1.1629 & 1.0430 & 0.9354 & 0.8389 & 0.7524 & \\
\hline & FD & 0.2692 & 0.4103 & 0.6252 & 0.9527 & 1.4517 & 2.2121 & 3.3708 & \\
\hline & FB & $1.7914^{*}$ & 1.4928 & $1.2440 *$ & 1.0367 & 0.8639 & 0.7199 & 0.5999 & \\
\hline & $\mathrm{HF}$ & 0.1435 & $0.3491 *$ & 0.8492 & 2.0659 & 5.0258 & 12.226 & 29.742 & \\
\hline & MRS & 0.0888 & 0.2543 & 0.7285 & $2.0867 *$ & 5.9776 & $17.123 *$ & $49.051 *$ & \\
\hline
\end{tabular}




\begin{tabular}{|l|l|l|l|l|l|l|l|l|l|}
\hline & CA & 0.1177 & 0.2259 & 0.4338 & 0.8329 & 1.5991 & 3.0703 & 5.8951 & 11.319 \\
& DC & 1.6349 & 1.4662 & 1.3150 & 1.1794 & 1.0577 & 0.9486 & 0.8508 & 0.7630 \\
& FD & 0.1739 & 0.2649 & 0.4037 & 0.6152 & 0.9374 & 1.4284 & 2.1766 & 3.3167 \\
& FB & $2.1756^{*}$ & $1.8130^{*}$ & $1.5108^{*}$ & $1.2590^{*}$ & 1.0492 & 0.8743 & 0.7286 & 0.6072 \\
& HF & 0.0751 & 0.1828 & 0.4446 & 1.0816 & 2.6312 & 6.4009 & 15.571 & 37.881 \\
& MRS & 0.0396 & 0.1134 & 0.3250 & 0.9309 & $2.6666^{*}$ & $7.6387^{*}$ & $21.882^{*}$ & $62.682^{*}$ \\
\hline \multirow{5}{*}{5} & CA & 0.0689 & 0.1323 & 0.2541 & 0.4878 & 0.9366 & 1.7983 & 3.4527 & 6.6292 \\
& DC & 1.8487 & 1.6580 & 1.4870 & 1.3336 & 1.1960 & 1.0727 & 0.9620 & 0.8628 \\
& FD & 0.1123 & 0.1711 & 0.2607 & 0.3972 & 0.6053 & 0.9224 & 1.4055 & 2.1417 \\
& FB & $2.6423^{*}$ & $2.2019 *$ & $1.8349^{*}$ & $1.5291^{*}$ & 1.2742 & 1.0619 & 0.8849 & 0.7374 \\
& HF & 0.0393 & 0.0957 & 0.2328 & 0.5663 & $1.3775^{*}$ & 3.3512 & 8.1523 & 19.832 \\
& MRS & 0.0177 & 0.0506 & 0.1450 & 0.4153 & 1.1896 & $3.4076^{*}$ & $9.7613^{*}$ & $27.962^{*}$ \\
\hline
\end{tabular}

Table 5. The Return on Investment by Companies by Steps and Days for Square root Model with Dif- ference Lag 4

\begin{tabular}{|c|c|c|c|c|c|c|c|c|c|}
\hline Days & Com & $\mathrm{i}=0$ & $\mathrm{i}=1$ & $i=2$ & $i=3$ & $\mathrm{i}=4$ & $i=5$ & $i=6$ & $i=7$ \\
\hline \multirow{6}{*}{1} & CA & 0.5276 & 1.0129 & & & & & & \\
\hline & DC & 1.1275 & 1.0112 & & & & & & \\
\hline & FD & 0.5154 & 0.7853 & & & & & & \\
\hline & FB & $1.2044 *$ & 1.0037 & & & & & & \\
\hline & $\mathrm{HF}$ & 0.5952 & $1.4478^{*}$ & & & & & & \\
\hline & MRS & 0.3423 & 0.9805 & & & & & & \\
\hline \multirow{6}{*}{2} & CA & 0.2783 & 0.5344 & 1.0261 & 1.9700 & 3.7824 & & & \\
\hline & DC & 1.2712 & 1.1401 & 1.0225 & 0.9170 & 0.8224 & & & \\
\hline & FD & 0.2656 & 0.4047 & 0.6168 & 0.9398 & 1.4321 & & & \\
\hline & FB & $1.4506^{*}$ & $1.2088^{*}$ & 1.0074 & 0.8395 & 0.6996 & & & \\
\hline & $\mathrm{HF}$ & 0.3542 & 0.8617 & $2.0963 *$ & $5.0996^{*}$ & $12.406^{*}$ & & & \\
\hline & MRS & 0.1172 & 0.3356 & 0.9614 & 2.7540 & 7.8892 & & & \\
\hline \multirow{6}{*}{3} & CA & 0.1468 & 0.2819 & 0.5413 & 1.0393 & 1.9955 & 3.8314 & 7.3563 & \\
\hline & DC & 1.4333 & 1.2854 & 1.1528 & 1.0339 & 0.9273 & 0.8316 & 0.7459 & \\
\hline & FD & 0.1369 & 0.2086 & 0.3179 & 0.4844 & 0.7381 & 1.1247 & 1.7138 & \\
\hline & FB & $1.7471^{*}$ & $1.4559^{*}$ & $1.2133^{*}$ & 1.0111 & 0.8426 & 0.7021 & 0.5851 & \\
\hline & $\mathrm{HF}$ & 0.2108 & 0.5129 & 1.2476 & $3.0351 *$ & $7.3834 *$ & $17.962 *$ & $43.695^{*}$ & \\
\hline & MRS & 0.0401 & 0.1149 & 0.3291 & 0.9427 & 2.7004 & 7.7354 & 22.159 & \\
\hline \multirow{6}{*}{4} & CA & 0.0775 & 0.1487 & 0.2856 & 0.5483 & 1.0528 & 2.0214 & 3.8810 & 7.4515 \\
\hline & $\mathrm{DC}$ & 1.6160 & 1.4493 & 1.2998 & 1.1667 & 1.0455 & 0.9377 & 0.8409 & 0.7542 \\
\hline & FD & 0.0706 & 0.1075 & 0.1638 & 0.2496 & 0.3804 & 0.5796 & 0.8833 & 1.3459 \\
\hline & FB & $2.1043^{*}$ & $1.7536^{*}$ & $1.4613^{*}$ & $1.2178^{*}$ & 1.0148 & 0.8457 & 0.7047 & 0.5873 \\
\hline & $\mathrm{HF}$ & 0.1255 & 0.3052 & 0.7425 & 1.8064 & $4.3943 *$ & $10.690 *$ & $26.006^{*}$ & $63.264 *$ \\
\hline & MRS & 0.0137 & 0.0393 & 0.1126 & 0.3227 & 0.9243 & 2.6478 & 7.5847 & 21.727 \\
\hline \multirow{6}{*}{5} & CA & 0.0409 & 0.0785 & 0.1507 & 0.2893 & 0.5554 & 1.0664 & 2.0475 & 3.9312 \\
\hline & $\mathrm{DC}$ & 1.8220 & 1.6341 & 1.4655 & 1.3244 & 1.1788 & 1.0572 & 0.9481 & 0.8504 \\
\hline & FD & 0.0364 & 0.0554 & 0.0844 & 0.1287 & 0.196 & 0.2987 & 0.4552 & 0.6937 \\
\hline & FB & $2.5344 *$ & $2.1120^{*}$ & $1.7600 *$ & $1.4667 *$ & $1.2222 *$ & 1.0185 & 0.8488 & 0.7073 \\
\hline & $\mathrm{HF}$ & 0.0747 & 0.1817 & 0.4419 & 1.0751 & 2.6153 & $6.3623^{*}$ & $15.478^{*}$ & $37.652 *$ \\
\hline & MRS & 0.0047 & 0.0135 & 0.0386 & 0.1104 & 0.3164 & 0.9063 & 2.5962 & 7.4369 \\
\hline
\end{tabular}

Table 6. The Return on Investment by Companies by Steps and Days for Negative Exponential Model with Difference Lag 4

\begin{tabular}{|l|l|l|l|l|l|l|l|l|l|}
\hline Days & Com & $\mathrm{i}=0$ & $\mathrm{i}=1$ & $\mathrm{i}=2$ & $\mathrm{i}=3$ & $\mathrm{i}=4$ & $\mathrm{i}=5$ & $\mathrm{i}=6$ & $\mathrm{i}=7$ \\
\hline \multirow{5}{*}{1} & CA & 1.5448 & 0.8046 & & & & & & \\
& DC & 0.8818 & $0.9832^{*}$ & & & & & & \\
& FD & 1.4816 & 0.9723 & & & & & & \\
& FB & 0.8166 & 0.9799 & & & & & & \\
& HF & 1.6066 & 0.6604 & & & & & & \\
& MRS & $1.7529^{*}$ & 0.6119 & & & & & & \\
\hline \multirow{5}{*}{2} & CA & 2.3864 & 1.2429 & 0.6473 & 0.3372 & 0.1756 & & & \\
& DC & 0.7776 & 0.8670 & 0.9667 & 1.0779 & 1.2018 & & & \\
& FD & 2.1952 & $1.4406^{*}$ & 0.9454 & 0.6204 & 0.4071 & & & \\
& FB & 0.6669 & 0.8002 & $0.9603^{*}$ & $1.1524^{*}$ & $1.3828^{*}$ & & & \\
& HF & 2.5812 & 1.0611 & 0.4362 & 0.1793 & 0.0737 & & & \\
& MRS & $3.0728^{*}$ & 1.0727 & 0.3745 & 0.1307 & 0.0456 & & & \\
\hline \multirow{5}{*}{3} & CA & 3.6864 & $1.9200^{*}$ & 1.0000 & 0.5208 & 0.2713 & 0.1413 & 0.0736 & \\
& DC & 0.6856 & 0.7645 & 0.8534 & $0.9505^{*}$ & $1.0598^{*}$ & $1.1817 *$ & 1.3176 & \\
& FD & 3.2524 & 2.1344 & $1.4007 *$ & 0.9192 & 0.6032 & 0.3959 & 0.2598 & \\
& FB & 0.5446 & 0.6535 & 0.7840 & 0.9410 & 1.1292 & 1.3551 & $1.6261 *$ & \\
& HF & 4.1471 & 1.7047 & 0.7008 & 0.2881 & 0.1184 & 0.0487 & 0.0200 & \\
& MRS & $5.3864^{*}$ & 1.8803 & 0.6564 & 0.2291 & 0.0800 & 0.0279 & 0.0097 & \\
\hline
\end{tabular}




\begin{tabular}{|l|l|l|l|l|l|l|l|l|l|}
\hline \multirow{5}{*}{4} & CA & 5.6947 & 2.9660 & 1.5448 & 0.8046 & 0.4190 & 0.2183 & 0.1137 & 0.0592 \\
& DC & 0.6046 & 0.6741 & 0.7517 & 0.8381 & 0.9345 & 1.0420 & 1.1618 & 1.2954 \\
& FD & 4.8188 & $3.1624 *$ & $2.0754^{*}$ & $1.3619^{*}$ & 0.8938 & $10.5865^{*}$ & 0.3849 & 0.2526 \\
& FB & 0.4447 & 0.5237 & 0.6404 & 0.7685 & $0.9222^{*}$ & 1.1066 & $1.3279 *$ & $1.5935^{*}$ \\
& HF & 6.6627 & 2.7388 & 1.1258 & 0.4628 & 0.1902 & 0.0782 & 0.0321 & 0.0132 \\
& MRS & $9.4420 *$ & 3.2961 & 1.1506 & 0.4017 & 0.1402 & 0.0490 & 0.0171 & 0.0060 \\
\hline \multirow{5}{*}{5} & CA & 8.7971 & 4.5818 & 2.3864 & 1.2429 & 0.6473 & 0.3372 & 0.1756 & 0.0915 \\
& DC & 0.5331 & 0.5944 & 0.6628 & 0.7390 & 0.8240 & $0.9188^{*}$ & 1.0245 & 1.1423 \\
& FD & 7.1396 & $4.6854 *$ & $3.0748^{*}$ & $2.0178 *$ & $1.3242 *$ & 0.8690 & $1.5703 *$ & 0.3742 \\
& FB & 0.3632 & 0.4358 & 0.5230 & 0.6275 & 0.7531 & 0.9037 & 1.0844 & $1.3013 *$ \\
& HF & 10.705 & 4.4003 & 1.8088 & 0.7435 & 0.3056 & 0.1256 & 0.0516 & 0.0212 \\
& MRS & $16.551 *$ & 5.7779 & 2.0170 & 0.7041 & 0.2458 & 0.0858 & 0.0300 & 0.0105 \\
\hline
\end{tabular}

It is observed that in Table (4), for same day the performance is increasing with the step for companies CA, FD, HF and MRS., decreasing with increasing in the step for companies DC and FB., decreasing with increasing in days for companies CA, FD, HF and MRS., increasing with increasing in days for companies DC and FB. Thus, company MRS gives the best performance on the basis of maximum ratio using differencing lag 4 .

Also,in Table (5): for same step the performance is decreasing with increasing days for companies $\mathrm{CA}, \mathrm{FD}, \mathrm{HF}$ and MRS., increasing with increasing days for companies DC and FB., increasing with increasing steps for companies CA, FD HF and MRS., decreasing with increasing steps for companies DC and FB., decreasing with increasing days for the companies DC, FB., increasing with increasing days for companies $\mathrm{CA}, \mathrm{FD}, \mathrm{HF}$ and MRS., decreasing with increasing steps for companies CA, FD, HF and MRS and increasing with increasing steps for companies DC and FB.

\section{Concluding Remarks}

Results were obtained for various models such as negative exponential model, logarithm model, square root model, and with power model being a generalization of square root model. The results were validated using data from some selected stocks such as Custodian and allied insurance plc (CA), Dangote cement plc (DC), Fidson Health-care plc (FD), First bank plc (FB), Honey-well flour mill plc (HF) and MRS Oil Nig plc (MRS) from some sectors such as financial services, consumer goods, health care, industrial goods and oil and gas of the Nigeria capital market. On the basis of this, company MRS is not recommended for investment. Of course, this can be attributed to the fact that it is not an active company. It was observed that return on investment with negative exponential model using difference lag 4 pays more than logarithm and square root models. This is with respect to amount of risk an investor is able to undertake in the hope of attaining greater wealth. From all the above, it is clear that the performance of the companies from day-to-day is determined by the ratio $\mathrm{q}: \mathrm{q}^{\prime}$ of the probability of rising to falling as well as the ratio $\mathrm{p}: \mathrm{p}^{\prime}$ of the risk neutral probability measure of rising to the falling.

Different return on investment with different models are provided by this article work to enable an investor to be equipped and enhanced with efficient and effective strategies of investment and allocation of their stalk irrespective of economic melt-down. Also, the data were only smoothened using moving averages and differencings, thus it could be extended for future work by Smoothing by single exponential model, Exponential smoothing with trend - Holt's model: Holt's twoparameter exponential smoothing model extends simple exponential smoothing to

include a linear-trend component, Winters' exponential smoothing: Winters three-parameter, exponential-smoothing model extends Holt's model by adding a seasonality factor, which is itself smoothed. Accordingly, we have three smoothing parameters, one for actual data, one for trend, and one for seasonal factors. 


\section{References}

[1] P. Battocchio, and F. Menoncin, Optimal Pension Management in a Stochastic Framework, Insurance: Mathematics and Economics, 34, 79-95, 2004.

[2] G. Deelstra, M. Grasselli, and P.-F. Koehl, Optimal Investment Strategies in the Presence of a Minimum Guarantee, Insurance: Mathematics and Economics, 33, 189-207, 2003.

[3] G. Deelstra, M. Grasselli, and P.-F. Koehl, Optimal Design of the Guarantee for Defined Contribution Funds, Journal of Economic Dynamics and Control, 28, 2239-2260, 2004.

[4] L.Delong, R. Gerrard, and S. Haberman, MeanVariance Optimization Problems for an Accumulation Phase in a Defined Benefit Plan, Insurance: Mathematics and Economics, 42, 107118, 2008.

[5] P. Emms, and S. Haberman, Asymptotic and Numerical Analysis of the Optimal Investment Strategy for An Insurer, Insurance: Mathematics an Economics, 40, 113-134, 2007.

[6] J. T. Eghwerido and T. O. Obilade, Optimization of Investment Returns with N- Step Utility Functions, Journal of the Nigerian Mathematical Society 33, 311-320, 2014.

[7] J. T. Eghwerido, E Efe-Eyefia, and E Ekuma-Okereke, Investment Returns with N- Step Generalized Utility Functions, ICASTOR Journal of Mathematical Sciences 9(2), 51-55, 2015.

[8] H. Hong-Chih Optimal Multiperiod Asset Allocation:Matching Assets to Liabilities in a Discrete Model, Journal of Risk and Insurance,77(2), 451-472, 2010.

[9] R. Korn, Worst-case scenario investment for insurers. Insur Math Econ 36, 1-11, 2005.

[10] R. Korn, and E. Korn, Option pricing and portfolio optimization. AMS, Providence, 2001.

[11] R. Korn and H. Kraft, Optimal portfolios with defaultable securities: a firms value approach. Int J Theory Appl Financ 6 793-819, 2003.

[12] R. Korn and O. Menkens, Worst-case scenario portfolio optimization: a new sto- chastic control approach. Math Methods Oper Res 62 (1) 123-140, 2005.

[13] H. Kraft and M. Steffensen, Portfolio problems stopping at first hitting time with application to default risk. Math Methods Oper Res 63, 123-150, 2006.

[14] Louis Bachelier's 'Theory of Speculation published by Princeton Press 1990, 1964

[15] MacDonald, B.-J., an A. J.G.Cairns, Getting Feedback on Defined Contribution Pension Plans, Journal of Risk and Insurance, 76(2), 385-417, 2009.

[16] Markowitz H., Portfolio selection, Journal of Finance 7, 77-91, 19, 2005.

[17] H. Martin, Martingale pricing applied to Dynamic Portfolio Optimization and Real Options, International Journal of Theoretical and Applied Finance, Vol 11, Issue 2005.

[18] J. Mulvey and B. Shetty, Financial Planning via Multi-Stage Stochastic Optimiza- tion, Computers and Operations Research, 31(1), 1-20, 2004.

[19] Oshorne The Econometric Modelling of Financial Time Series, Second Edition Terence Mills, http://www.cambridge.org/

[20] H. Pham, On some recent aspects of stochastic control and their applications, Probability Surveys 2 506-549, 2005.

[21] L.C.G. Rogers, The relaxed investor and parameter uncertainty Finance Stochastic 5, 131-154, 2001.

[22] W. Schachermayer, Utility maximization in incomplete markets, In: Stochastic methods in finance, Lectures given at the CIME-EMS Summer in Bressanone/Brixen, Italy, (M.Fritelli, W. Runggladier, eds.), Springer Lecture notes in Mathematics, 1856, 2003.

[23] M. Schweizer, 'A guided tour through quadratic hedging approaches', in option pricing interest rates, and risk management, eds. Jouini E., Museiela M., Cvitanic J., Cambridge university Press, 538-574, 2001.

[24] Von-Neumann and Morgenstern Theory of games and economic behavior, Princeton University Press. 